\title{
Implementação de Signos Distintivos para as Pedras de Pirenópolis: marca ou indicação geográfica
}

\author{
Implementation of Distinctive Signs for "Pedras De Pirenópolis" \\ (Pirenópolis Stones): geographical mark or index
}

\author{
Alessandro Aveni ${ }^{1}$ \\ Pedro Anisio de Camargo Alves ${ }^{1}$ \\ Priscilla Marmentini ${ }^{1}$ \\ ${ }^{1}$ Universidade de Brasília, Brasília, DF, Brasil
}

\begin{abstract}
Resumo
Estudo sobre a viabilidade de implantação de signos distintivos para as Pedras de Pirenópolis com recomendação da escolha de Marca ou de Indicação Geográfica de acordo com os objetivos da entidade requerente (pessoa jurídica interessada no registro da Marca ou da Indicação Geográfica e que detenha legitimidade). O nome "Pedras de Pirenópolis" possui destaque no mercado nacional de pisos e revestimentos, e distingue-se dos outros produtos similares no mercado.
\end{abstract}

Palavras-chave: Indicação Geográfica. Marca. Pedras de Pirenópolis.

\begin{abstract}
Study on the feasibility of distinctive signs implementation for the "Pedras de Pirenópolis" (Pirenópolis Stones) with the recommendation of Mark or Geographical Indication according to the objectives of the requesting entity (legitimate entity interested in registering the Mark or Geographical Indication). The name "Pedras de Pirenópolis" already stands out in the national market for floors and coatings, and is distinguished from other similar products.

Keywords: Geographical Indication. Brand. Pirenópolis Stones.

Área tecnológica: Tecnologia Mineral.
\end{abstract}

\section{Introdução}

A Marca e a Indicação Geográfica (IG) são signos distintivos por nomes ou elementos gráficos que diferenciam produtos ou serviços por sua origem, qualidade, produtor ou outras características intrínsecas. O uso adequado dessas ferramentas coloca o produto ou serviço em vantagem com relação aos seus concorrentes.

A IG, consoante definição contida no sítio eletrônico do Instituto Nacional da Propriedade Industrial (INPI), é usada para identificar a origem de produtos ou serviços quando o local tenha se tornado conhecido ou quando determinada característica ou qualidade do produto ou 
serviço se deve a sua origem (INPI, 2015). No Brasil, ela tem duas modalidades: Denominação de Origem (DO) e Indicação de Procedência (IP).

Já a Marca, consoante definição contida no sítio eletrônico do Serviço Brasileiro de Apoio às Micro e Pequenas Empresas (SEBRAE), é todo sinal distintivo, visualmente perceptível, que identifica e distingue produtos e serviços, bem como certifica a sua conformidade com determinadas normas ou especificações técnicas (SEBRAE, 2016). A marca registrada garante ao seu proprietário o direito de uso exclusivo no território nacional em seu ramo de atividade econômica e, simultaneamente, pode resultar em agregação de valor aos produtos ou serviços perante o consumidor.

Os signos distintivos tendem a representar qualidade, valor, tradição, seriedade, familiaridade e/ou satisfação, de modo que os produtos se destacam da concorrência e fidelizam consumidores ao criar uma relação de confiança entre o produto ou serviço e o seu comprador.

Com isto, produtos ou serviços associados à Marca ou à IG possuem importante ferramenta de distinção coletiva e valorização, o que se traduz em inúmeras possibilidades de valorização, divulgação, aumento de rentabilidade, melhoria nos processos produtivos, entre outros benefícios.

No entanto, antes de escolher qual signo distintivo utilizar, é necessário entender o que é a Marca e a IG, os requisitos para o registro bem como as características de cada um.

\section{Metodologia}

O presente estudo se baseou em material disponibilizado em sítios eletrônicos. A pesquisa também ocorreu por meio de fontes bibliográficas e dados obtidos por comunicação telefônica com contato da Prefeitura de Pirenópolis e da Associação dos Mineradores de Pirenópolis (AMIP). A pesquisa foi considerada "exploratória" haja vista ter tido o propósito de "[...] proporcionar maior familiaridade com o problema, com vistas a torná-lo mais explícito ou a construir hipóteses." (GIL, 2010, p. 27).

\section{Resultados e Discussão}

\subsection{Marca}

De acordo com o ordenamento jurídico vigente, para ter exclusividade sobre o nome de um produto ou serviço ou, ainda, um logotipo que o identifique, é preciso registrar uma Marca, o que garante ao seu titular o direito de uso exclusivo no território nacional em seu ramo de atividade econômica pelo período de dez anos, a partir da data da concessão. O registro pode ser prorrogado indefinidamente por sucessivos períodos de dez anos, conforme o artigo 133 Lei de Propriedade Industrial (LPI), Lei nº 9.279, de 14 de maio de 1996.

O artigo 123 da LPI diferencia marca de produto ou serviço da Marca de Certificação e Marca Coletiva e classifica Marca como aquela usada para distinguir produto ou serviço de outro idêntico, semelhante ou afim, de origem diversa; sendo Marca de Certificação aquela usada para atestar a conformidade de um produto ou serviço com determinadas normas ou 
especificações técnicas, notadamente quanto à qualidade, natureza, ao material utilizado e à metodologia empregada; e Marca Coletiva aquela usada para identificar produtos ou serviços provindos de membros de uma determinada entidade.

A Marca Coletiva possui finalidade distinta das marcas de produto e de serviço. O objetivo da Marca Coletiva é indicar ao consumidor que aquele produto ou serviço provém de membros de uma determinada entidade.

É importante destacar que a marca coletiva pode ser utilizada pelos membros da entidade detentora do registro, sem necessidade de licença de uso, desde que estejam previstos no regulamento de utilização da marca. Por sua vez, o titular da marca pode estabelecer condições e proibições de uso para seus associados por meio de um regulamento de utilização. Nesse caso, caberá ao regulamento definir as regras para a utilização da marca pelos membros da entidade.

Outra hipótese a ser considerada é a Marca de Certificação. Em síntese é aquela usada para atestar a conformidade de um produto ou serviço com determinadas normas, padrões ou especificações técnicas, notadamente quanto à qualidade, à natureza, ao material utilizado e à metodologia empregada (artigo 123, inciso II, da LPI). A Marca de Certificação possui finalidade distinta das marcas de produto e de serviço e o objetivo é informar ao público que o produto ou serviço está de acordo com normas ou padrões técnicos específicos.

Nos moldes da LPI, a Marca de Certificação pode ser utilizada somente por terceiros autorizados pelo titular depois de atestada a conformidade do produto ou serviço aos requisitos técnicos. Cumpridos os requisitos, o interessado está apto a incorporar em seu produto ou serviço a Marca de Certificação registrada no INPI.

Cabe ressaltar que uma marca dessa natureza não substitui, nem dispensa os selos de inspeção sanitária ou o cumprimento de qualquer regulamento ou norma específica para produto ou serviço estabelecidos pela legislação vigente.

A obtenção de Marca de Certificação não exime a responsabilidade do fornecedor em garantir a qualidade do produto ou serviço.

\subsection{Indicação Geográfica}

Os signos distintivos como as indicações geográficas são conhecidas e utilizadas há muito tempo como forma de agregar valor a serviços e produtos tradicionais produzidos em países, como França, Portugal e Itália.

A IG no Brasil é recente e foi introduzido na LPI que estabeleceu as modalidades Indicação de Procedência e Denominação de Origem (artigo 176, da LPI), estabelecendo como característica comum que o nome geográfico é referente ao local (país, cidade, região ou localidade de seu território) e como diferença essencial que a Denominação de Origem se refere a produto ou serviço cujas qualidades ou características se devam exclusiva ou essencialmente ao meio geográfico, incluídos fatores naturais e humanos (artigos 176 e 177, da LPI).

A proteção concedida é estendida à representação gráfica ou figurativa da indicação geográfica e à representação geográfica de país, cidade, região ou localidade de seu território cujo nome seja indicação geográfica (artigo 179, da LPI).

A LPI permite que o nome geográfico que não seja indicação geográfica possa servir de elemento característico de marca para produto ou serviço, desde que não induza falsa pro- 
cedência (artigo 181, da LPI) e veda ao nome geográfico de uso comum se tornar indicação geográfica (artigo 180, da LPI).

O registro no INPI possui natureza declaratória e implica no reconhecimento das Indicações Geográficas. Uma vez concedida a IG, seu uso é restrito aos produtores e prestadores de serviço estabelecidos no local. Caso seja denominação de origem, os requisitos de qualidade estabelecidos devem ser atendidos pelos legitimados.

A LPI regula direitos e obrigações relativos à Propriedade Ondustrial e atribui ao INPI a competência para estabelecer as condições de registro das indicações geográficas (parágrafo único do artigo 182, da LPI).

As normas do INPI que regulam a IG são a Instrução Normativa 25, de 21 de agosto de 2013, que estabelece as condições para o registro das IG, e a Resolução Normativa n 55, de 18 de março de 2013, que dispõe sobre o depósito dos pedidos de registro de desenho industrial e dos pedidos de registro de indicação geográfica e dos procedimentos relativos à numeração desses pedidos.

As regras gerais para a solicitação do pedido de registro de IG, conforme estabelecido na IN 25/2013, são o requerimento com o nome geográfico e a descrição do produto ou serviço; instrumento hábil a comprovar a legitimidade do requerente; regulamento de uso do nome geográfico; instrumento oficial que delimita a área geográfica emitido pelo órgão competente de cada estado (artigo $7^{\circ}$, da IN 25/2013); etiquetas, quando se tratar de representação gráfica ou figurativa da Indicação geográfica ou de representação de país, cidade, região ou localidade do território, bem como sua versão em arquivo eletrônico de imagem; procuração, se for o caso; comprovante do pagamento da GRU (artigo 6 , da IN 25/2013).

No caso da Indicação de Procedência, é necessária, além dos documentos descritos, a apresentação de elementos que comprovem ter o nome geográfico se tornado conhecido como centro de extração, produção ou fabricação do produto ou prestação do serviço, e, no caso de Denominação de Origem, deverá ser apresentada elementos que comprovem que as qualidades e/ou características do produto ou serviço se devam, exclusiva ou essencialmente, ao meio geográfico, incluindo fatores naturais e humanos.

Ademais, é indispensável a prova do estabelecimento dos produtores ou prestadores de serviços na área geográfica demarcada com efetivo exercício das atividades de produção ou prestação do serviço.

No caso da Indicação de Procedência, o pedido de registro também deve conter documentos que comprovem o preenchimento de requisitos legais específicos que justifiquem o registro (artigo $8^{\circ}$, da IN 25/2013).

Cabe ao requerente comprovar que o nome geográfico se tornou conhecido como centro de extração, produção ou fabricação do produto ou de prestação de serviço por meio de documentos.

No caso de Denominação de Origem, os requisitos específicos do pedido determinados pelo INPI são elementos que identifiquem a influência do meio geográfico no produto, descrição do processo, existência de estrutura de controle, estabelecimento dos produtores na área geográfica demarcada (artigo 9 ${ }^{\circ}$ da IN 25/2013).

No pedido de registro devem contar elementos que identifiquem a influência essencial do meio geográfico na qualidade ou características do produto ou serviço, incluindo fatores naturais 
e humanos, bem como a descrição do processo ou método de obtenção do produto ou serviço, que devem ser locais, leais e constantes.

Tanto para o registro da Indicação de Procedência quanto da Denominação de Origem são exigidos documentos que demonstrem a existência de estrutura de controle sobre os produtores ou prestadores de serviços que tenham o direito ao uso exclusivo da Indicação de Procedência, bem como sobre o produto ou a prestação do serviço.

A IN 25/2013 é taxativa quanto ao rol dos legitimados para requerer o registro no INPI, que pode ser solicitado em nome próprio ou na qualidade de substitutos processuais.

O produtor ou prestador de serviço que possuir legitimidade exclusiva para o uso do nome geográfico poderá requerer em nome próprio ( $\$ 1^{\circ}$ do artigo $5^{\circ}$, da IN $25 / 2013$ ) e o titular do direito sobre a IG estrangeira é o deve requerer o registro ( $\$ 2^{\circ}$ do artigo $5^{\circ}$, da IN 25/2013).

Podem requerer o registro de IG, na qualidade de substitutos processuais, as associações, os institutos e as pessoas jurídicas representativas da coletividade legitimada ao uso exclusivo do nome geográfico estabelecidas no respectivo território (artigo $5^{\circ}$, da IN 25/2013).

Um exemplo de legitimidade representativa são os sindicatos. $\mathrm{O}$ inciso III, do artigo $8^{\circ}$, da Constituição Federal determina "[...] ao sindicato cabe a defesa dos direitos e interesses coletivos ou individuais da categoria, inclusive em questões judiciais ou administrativas." (BRASIL, 1988).

O registro do nome geográfico pressupõe a existência de uma estrutura de controle sobre os produtores ou prestadores que tenham o direito ao uso exclusivo da IG bem como ao produto ou prestação do serviço distinguido pela IG, sendo essencial o estabelecimento de critérios para o uso do signo distintivo e a manutenção da qualidade.

Para o registro, o controle de uso é necessário nas duas modalidades de IG e, em regra, é feito por intermédio de regulamento que estabeleça requisitos que devem ser atendidos para que o produto ou serviço possa ser aprovado como sendo um produto de IG e receber o Atestado de Conformidade do produto e a Autorização para uso do signo da IG.

O sistema de controle de uso que garanta a qualidade e as características do produto é essencial para a manutenção e sucesso da IG.

O Processo de Registro é facilitado pelo INPI que disponibiliza em seu site formulário próprio de pedido de registro, lista de documentos necessários, link para gerar a Guia de Recolhimento da União (GRU) e outras informações úteis.

Cabe ao requerente, depois da a análise do cumprimento dos requisitos legais e da elaboração dos documentos comprobatórios, preencher o formulário de solicitação de registro específico na forma determinada, gerar e pagar a GRU.

É essencial a descrição adequada do produto ou serviço, com as suas características, a representação gráfica ou figurativa da IG, caso exista e a comprovação de que os produtores ou prestadores de serviços estão estabelecidos na área geográfica demarcada e exercendo a atividade econômica no local que buscam proteger;

Todos os documentos deverão ser cópia fiel dos originais e acompanhados da devida declaração de veracidade.

O pedido de IG depositado no INPI é submetido a exame formal para verificação da adequação dos documentos, conforme estipulado na IN 25/2013. Eventuais exigências do INPI 
devem ser respondidas no prazo de 60 dias por meio de formulário próprio, acompanhado da taxa correspondente, sob pena de arquivamento definitivo.

Concluída a análise, o pedido de registro será publicado. Terceiros interessados terão 60 dias para manifestação que será publicada na Revista Eletrônica de Propriedade Industrial (RPI $)^{1}$, com prazo de 60 dias para contestação do requerente.

Encerrados os prazos previstos, será efetuado o exame do pedido por técnicos do INPI que subsidiarão a decisão deferindo ou indeferindo o pedido de reconhecimento à IG.

Caso a decisão seja pelo reconhecimento da IG, o INPI emitirá o Certificado de Registro. Caso o pedido seja negado, a requerente ainda poderá recorrer administrativamente no prazo de 60 dias. Os terceiros interessados possuem legitimidade para recorrer.

O recurso contra a decisão do pedido de registro de IG deverá ser efetuado por meio de formulário acompanhado da respectiva Guia paga. Os recursos serão decididos pelo presidente do INPI.

Caso o registro seja negado pelo INPI, o requerente poderá juntar novas informações e requerer novamente o registro de $\mathrm{IG} .^{2}$

Com o registro, o produto obterá a diferenciação no mercado por intermédio da indicação geográfica, com a proteção da IG, evitando a utilização indevida.

O registro da IG delimitará a área geográfica, restringirá o uso aos produtores e prestadores de serviços da região (em geral, organizados em entidades representativas), manterá os padrões de qualidade e impedirá o uso indevido do nome geográfico.

Depois do registro, não existe prazo de validade e a proteção legal vigorará enquanto durarem os requisitos autorizadores para a IG.

\subsection{As Pedras de Pirenópolis}

O caso das Pedras de Pirenópolis é singular. Trata-se de cidade tombada pelo Patrimônio Histórico, onde boa parte das construções é feita com "Pedras de Pirenópolis".

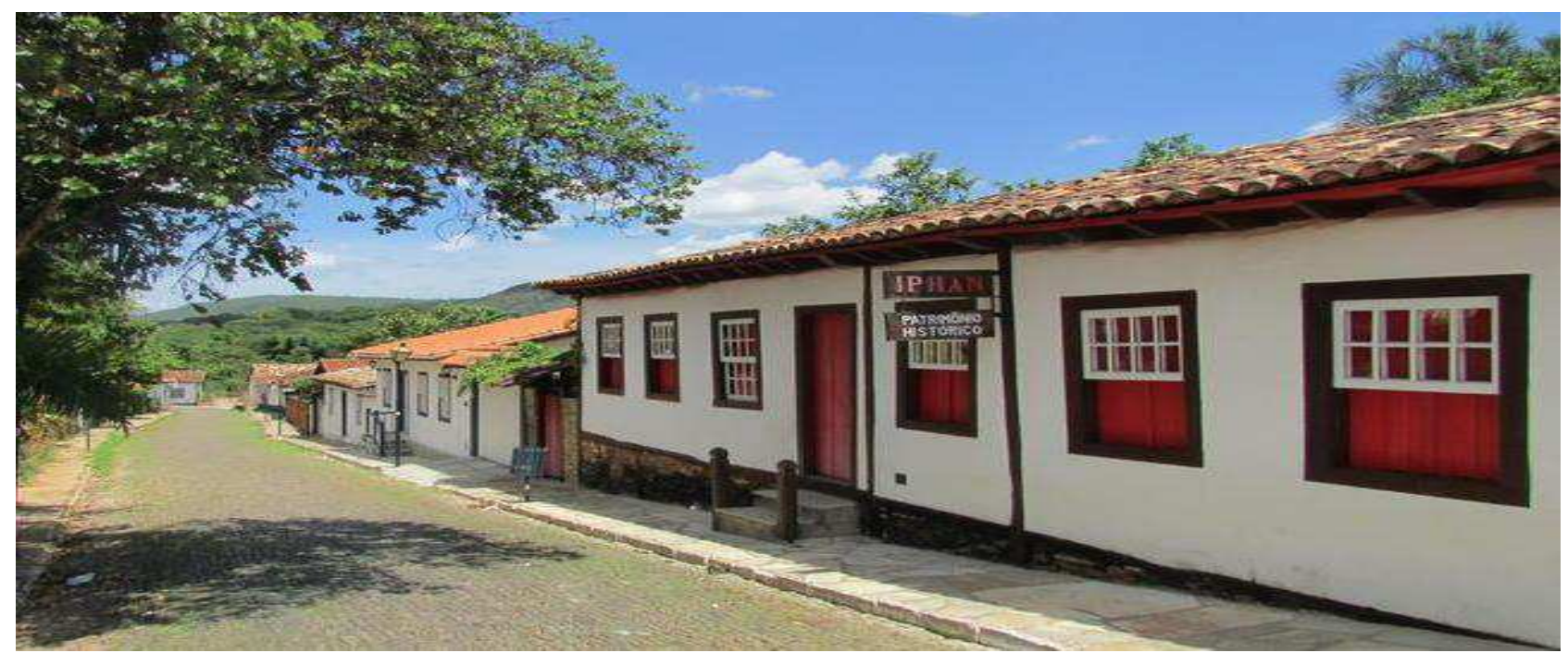

Fonte: Vemprapiri (2017)

\footnotetext{
${ }^{1}$ As RPIs estão disponíveis em: <http://revistas.inpi.gov.br/rpi/>. Acesso em: 27 maio 2018.

${ }^{2}$ Adaptado da Instrução Normativa n ${ }^{\circ}$ 25/2013 e do conteúdo disponível em: <http://www.inpi.gov.br/menu-servicos/indicacao-geografica>. Acesso em: 10 jun. 2018.
} 
Consoante informações do site do Wikipedia, Pirenópolis é um município histórico, sendo um dos primeiros do estado de Goiás. Foi fundado com o nome de Minas de Nossa Senhora do Rosário Meia Ponte e, em 1890, a cidade teve seu nome mudado para Pirenópolis, o município dos Pireneus, nome dado à serra que a circunda. Ficou isolada durante grande parte do século XX e redescoberta da década de 1970, com a construção da nova capital do país, Brasília. Hoje, é famosa pela produção das Pedras de Pirenópolis e pelo turismo (PIRINÓPOLIS, [2018b]).

Tombada como conjunto arquitetônico, urbanístico, paisagístico e histórico pelo Instituto do Patrimônio Histórico e Artístico Nacional (IPHAN), em 1989, o município conta com um Centro Histórico ornado com casarões e igrejas do século XVIII, como a Igreja Matriz de Nossa Senhora do Rosário (1728-1732), a Igreja de Nossa Senhora do Carmo (1750-1754) e a Igreja de Nosso Senhor do Bonfim (1750-1754), além de prédios de relevante beleza arquitetônica como o Teatro de Pirenópolis, de estilo híbrido entre o colonial e neoclássico, de 1899, e o Cine Teatro Pireneus, em estilo art-déco, de 1919 e a Casa de Câmara e Cadeia construída em 1919 como réplica idêntica do original de $1733 .^{3}$

Sobre a geografia, consoante Figura 1, Pirenópolis é localizada a uma latitude 1551'09" sul e a uma longitude 48 57'33" oeste, estando a sede a uma altitude de 770 metros. Sua população em 2017, segundo censo do IBGE, foi de 24.761 habitantes. Possui uma área de 2.205,01 km² (IBGE, [2018])

Figura 1 - Município de Pirenópolis
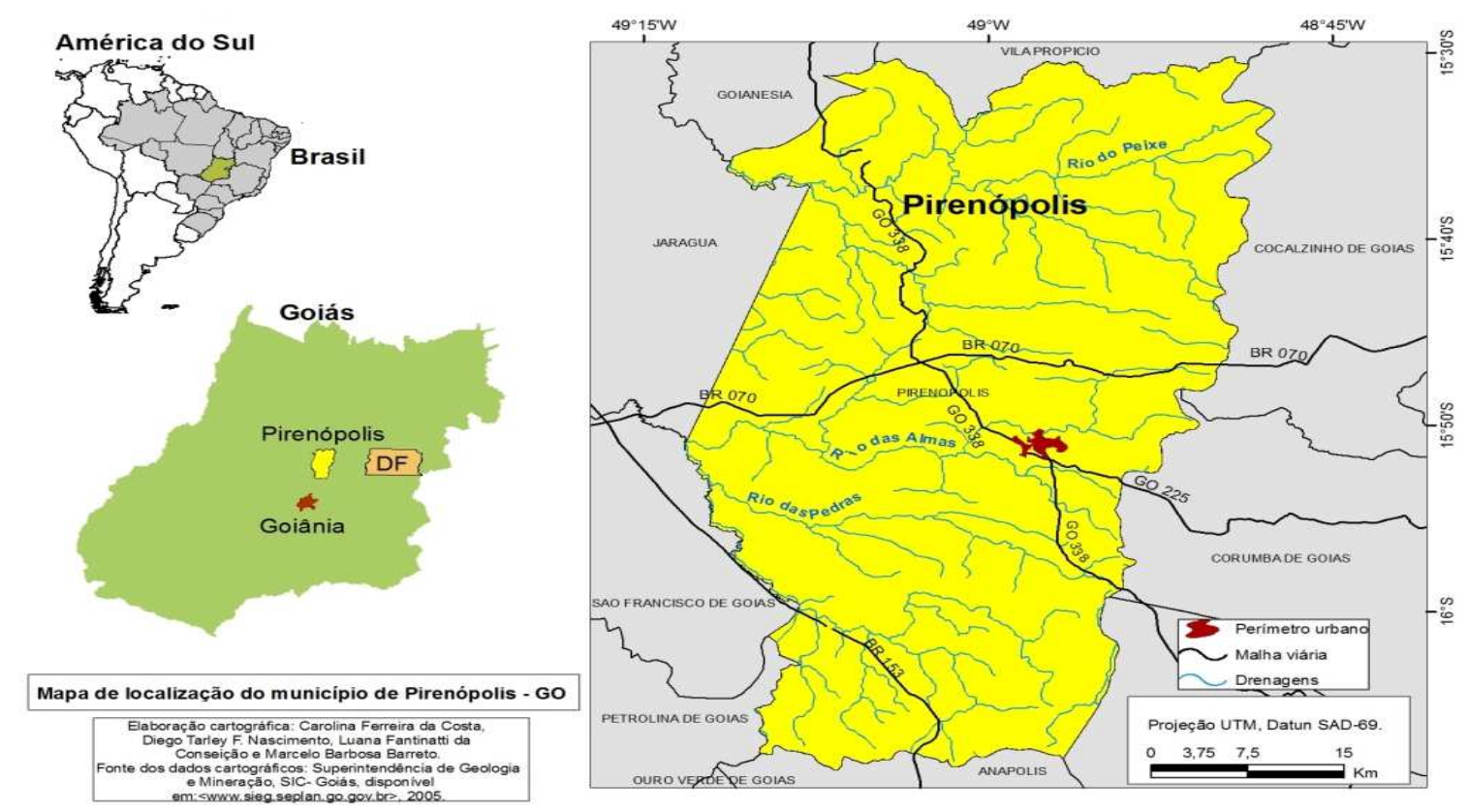

Fonte: Conceição et al. (2009, p. 78)

O município está localizado no Planalto Central Brasileiro e devido à sua topografia, as formações do seu relevo provêm matéria-prima para a exploração mineral do quartzito, rocha muito usada na construção civil, especialmente para pisos exteriores, conhecida comercialmente como Pedra de Pirenópolis (PIRENÓPOLIS, [2018a]).

\footnotetext{
${ }^{3}$ Ficha Técnica: Nome: Conjunto Arquitetônico, Urbanístico, Paisagístico e Histórico de Pirenópolis; Município: Pirenópolis; Estado: Goiás; Superintendência Regional do Iphan: 14ª ; Área do perímetro tombamento: 17 ha; No Processo: 1181-T-85.

Características do Tombamento Federal: Livro Arqueológico, Etnográfico e Paisagístico; Data: 10 de janeiro de 1990; Inscrição:105; Livro do Tombo: Histórico Vl.2; Inscrição: 530; Data: 10 de janeiro de 1990.
} 
Além disto, é privilegiada no potencial turístico, possui clima agradável e a presença de centenas de cachoeiras, que agradam aos ecoturistas e amantes da natureza.

As Pedras de Pirenópolis são amplamente utilizadas na construção civil, possuindo nome com forte apelo de qualidade mesmo sem nenhum signo distintivo. É fácil distinguir as Pedras de Pirenópolis de outros produtos similares no mercado.

No município de Pirenópolis a maior pedreira é de propriedade da prefeitura. Existem cerca de 500 mineradores, incluídos extratores, lapidadores, responsáveis pelo transporte, entre outros, envolvidos na produção das pedras. A maior pedreira do município é de propriedade da prefeitura, mas existem pelo menos mais 17 empresas comprometidas com a mineração $e$ que participam ativamente da AMIP.

A importância das Pedras de Pirenópolis para o município é refletida na economia, sendo responsável pela maior parte de geração de renda da cidade ${ }^{4}$, apesar dos bons números alcançados pelo turismo.

O desempenho de Pirenópolis no setor mineral no ano base 2016 com exercício em 2017 foi disponibilizado no site da Agência Nacional de Mineração na publicação "Desempenho do Setor Mineral" (AGÊNCIA NACIONAL DE MINERAÇÃO, 2017) e avulta o significado da mineração na economia em Pirenópolis, exibindo o potencial por meio de apontamentos estatísticos de quantidade e de valor, objetivando indicar medidas de melhor aproveitamento econômico.

Da mencionada publicação, destacam-se na Tabela 1 os seguintes dados referentes ao município de Pirenópolis sobre reservas, produção e venda.

E na Tabela 2 constam os dados sobre produção e comercialização, em especial, de rochas para revestimento, como a "Pedra de Pirenópolis":

Tabela 1 - Reservas minerais por município/substância, do estado de Goiás e Distrito Federal

\begin{tabular}{|c|c|c|c|c|}
\hline \multirow{2}{*}{$\begin{array}{c}\text { MunicíPIO/SUBSTÂNCIA } \\
\text { UNIDADE }\end{array}$} & \multicolumn{4}{|c|}{ RESERVAS } \\
\hline & TONELADA & MEDIDA & INDICADA & INFERIDA \\
\hline Pirenópolis & & 133.413 .504 & 20.906 .420 & 434.222 \\
\hline
\end{tabular}

Fonte: Agência Nacional de Mineração (2017)

Tabela 2 - Produção e comercialização, por município/substância do estado de Goiás e Distrito Federal em 2016 (em toneladas)

\begin{tabular}{cccc} 
Municírio/substância & Produção & Quntidade & Venda \\
Pirenópolis & & & $\mathbf{7 . 9 8 6 . 9 7 2 , 6 0}$ \\
Areia & $1.688,00$ & $1.491,00$ & $19.170,00$ \\
Areia & 300,00 & 300,00 & $6.000,00$ \\
Calcário agrícola & $5.700,00$ & $5.000,00$ & $44.000,00$ \\
Rochas para revestimento & $\mathbf{2 8 . 7 0 0 , 1 7}$ & $\mathbf{2 8 . 7 0 0 , 1 7}$ & $\mathbf{7 . 9 1 7 . 8 0 2 . 6 0}$ \\
\hline
\end{tabular}

Fonte: Agência Nacional de Mineração (2017)

${ }^{4}$ Informação fornecida em entrevista telefônica com funcionários da AMIP. 
Resta comprovada a importância e a dependência econômica do município de Pirenópolis com a mineração, apesar do aumento dos ganhos com o turismo.

Ademais, considerando o fato que o signo distintivo escolhido levará o nome da cidade, além do potencial econômico direto, há uma expectativa de aumento de renda indireta com o turismo, advindos da fortificação do nome do município com as Pedras de Pirenópolis.

\subsection{O Caso da Denominação de Origem das Pedras do Noroeste do Rio de Janeiro}

Três casos de IG que devem ser analisados com atenção. São os da Denominação de Origem na região noroeste do Rio de Janeiro, os quais são semelhantes ao caso das Pedras de Pirenópolis.

O requerente foi o Sindicato de Extração e Aparelhamento de Gnaisses no Noroeste do Estado do Rio de Janeiro (SINDGNAISSES), CNPJ 04.766.795/0001-02, pessoa jurídica que possui legitimidade para defender em juízo os direitos e interesses coletivos ou individuais dos integrantes da categoria que representam na forma do inciso III, do artigo $8^{\circ}$, da Constituição Federal.

A delimitação da Denominação de Origem foi fundamentada em critérios geológicos e a sua localização definida na região noroeste do estado do Rio de Janeiro com indicação das coordenadas extremas.

O nome geográfico atribuído foi relacionado às pedras e ao estado de origem, a saber "Região Pedra Carijó Rio de Janeiro", "Região Pedra Madeira Rio de Janeiro" e "Região Pedra Cinza Rio de Janeiro".

A descrição do produto seguiu suas características físicas, forma de extração e manejo antes da comercialização, com uso do nome científico e popular das pedras.

O caso da Denominação de Origem das Pedras do Noroeste do Rio de Janeiro é um exemplo de sucesso da IG. Depois da implementação desse signo distintivo, é possível medir o aumento na divulgação da região como produtora de pedras de qualidade para revestimento. Desde que foi registrado, a Denominação de Origem contribuiu para o desenvolvimento regional do noroeste do Rio de Janeiro, principalmente para os produtores envolvidos.

\subsection{Pedras de Pirenópolis: marca ou indicação geográfica}

No caso das Pedras de Pirenópolis os dois signos distintivos se mostram viáveis, pois preenchem os requisitos legais tanto da Marca quanto da IG.

Pode ser criada uma Marca de Certificação para atestar a conformidade das pedras com normas a serem produzidas e que estipulem e especificações técnicas quanto à qualidade, à natureza, ao material utilizado, à metodologia na extração, à lapidação e preparação das pedras. A Marca de Certificação serviria para informar ao público que o produto ou serviço está de acordo com normas ou padrões técnicos específicos.

Também vislumbramos a possibilidade das entidades envolvidas com a mineração criarem uma Marca Coletiva que seria usada para identificar que as Pedras de Pirenópolis são aquelas provenientes de determinada entidade do município de Pirenópolis, que poderia ser a AMIP, desde que seja devidamente legitimada pelos envolvidos na mineração do município. 
No caso, a AMIP estabeleceria condições e proibições de uso para seus associados por meio de um regulamento de utilização, com as regras para a utilização da marca pelos membros da entidade. Com isto, os associados utilizariam a Marca Coletiva criada sem necessidade de licença de uso.

No entanto, caso signo distintivo seja IG, as Pedras de Pirenópolis poderiam ser registradas tanto como Indicação de Procedência, em razão do município ser o centro de extração das pedras ou Denominação de Origem em razão das Pedras de Pirenópolis designarem produtos cujas qualidades e características se devem essencialmente ao meio geográfico, incluídos fatores naturais e humanos. Os fatores de qualidade e as características das Pedras de Pirenópolis são oriundas da formação geológica da região, que acabam por gerar pedras com forma, qualidade e coloração singulares, com resistência que permite a aplicação em diversas áreas de revestimento da construção civil.

O município de Pirenópolis (Figura 2) faz parte da unidade geotectônica da Faixa Brasília, representada como um cinturão móvel, depositado e deformado na margem oeste do Craton São Francisco, sobre um embasamento constituído por terrenos granitognassicos paleoproterozoicos afetados por um sistema de dobramentos neoproterozoicos. E cadeia orogenética antiga e formada, dentre outros, pelo Grupo Araxá e pela Sequência Metavulcanossedimentar do Rio do Peixe -grupos representantes da estrutura geológica de Pirenópolis Conceição et al. (2009).

Figura 2 - Perfil geológico de Pirenópolis
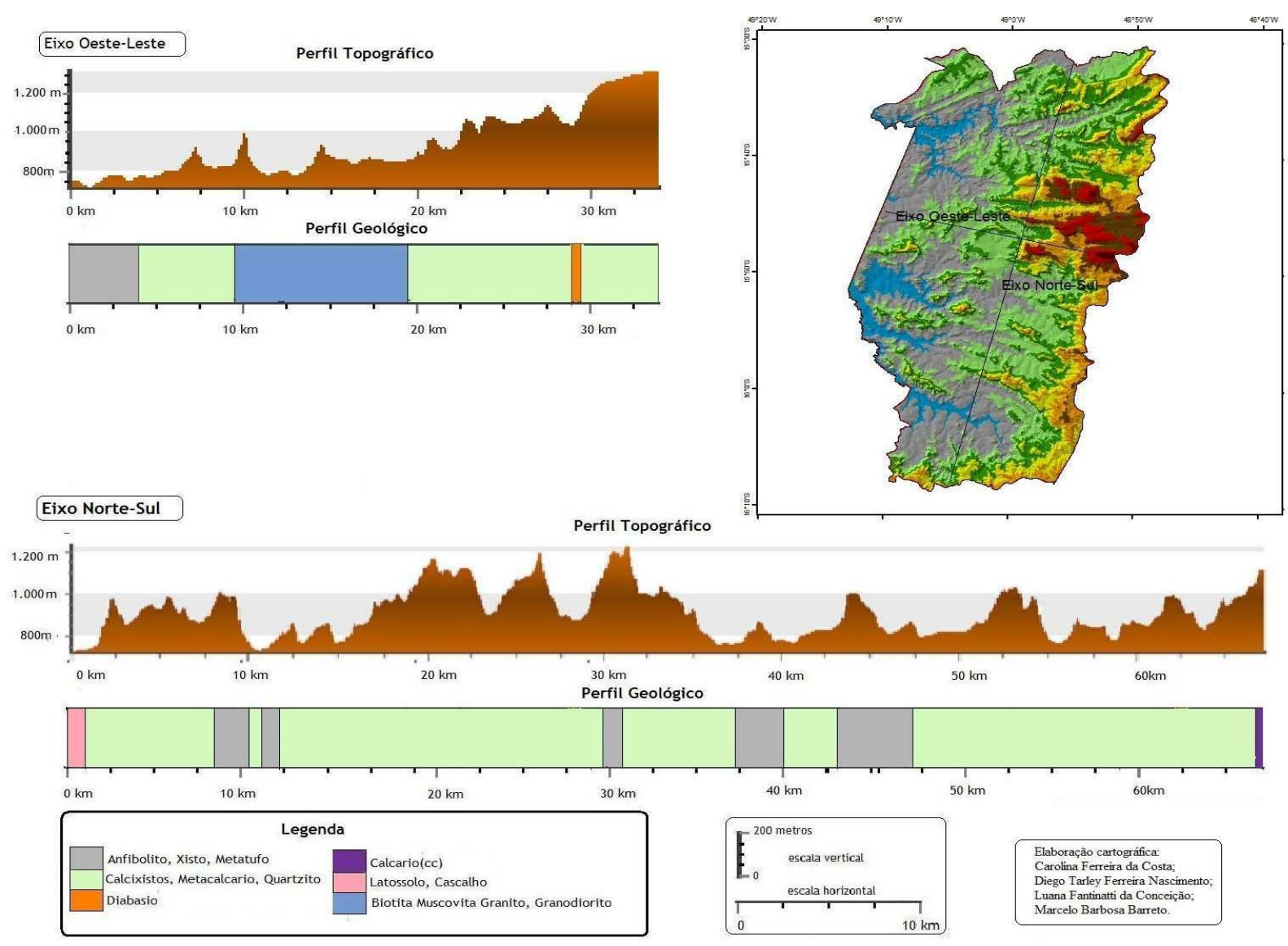

Fonte: Conceição et al. (2009, p. 85) 
A definição da legitimidade para requerer o registro do nome geográfico reside na prova do estabelecimento dos produtores com efetivo exercício das atividades de produção. No município de Pirenópolis existe a AMIP, na qual são associadas 17 empresas envolvidas diretamente com a mineração das Pedras de Pirenópolis.

No entanto, caso essa entidade não demonstre força e representatividade entre a maioria absoluta dos mineradores e produtores da região, os quais são os legítimos detentores do nome geográfico, é prudente a criação do Sindicato dos Mineradores das Pedras de Pirenópolis, o qual deteria legitimidade representativa, na forma definida no inciso III, do artigo $8^{\circ}$, da Constituição Federal, para requerer o registro da IG.

A área geográfica deve ser delimitada de acordo com critérios técnicos, geográficos, humanos e sociais, no presente caso, os limites devem ser coincidentes com os do município de Pirenópolis.

O Regulamento de Uso da Indicação Geográfica das Pedras de Pirenópolis deve ser estruturado de forma que assegure que o produto atenda aos requisitos de qualidade e as características estabelecidas.

É importante constar, no mínimo:

a) nome geográfico;

b) área geográfica delimitada com descrição da delimitação da área geográfica;

c) forma autorizada de extração das pedras de pirenópolis;

d) a produtividade máxima das mineradoras;

e) os critérios de qualidade mínima das Pedras de Pirenópolis;

f) a área de produção autorizada;

g) os padrões de identidade e características analíticas distintivas das Pedras de Pirenópolis;

h) categorias de todas Pedras de Pirenópolis (caso exista mais de uma);

i) a área geográfica de extração das pedras;

j) os padrões de identidade das Pedras de Pirenópolis;

k) instituição de conselho regulador para gerir a IG com sistema de controle para assegurar o cumprimento do regulamento de uso;

1) direitos e obrigações dos produtores;

m) especificar as infrações e as sanções aplicáveis às infrações à indicação de procedência ou denominação de origem;

n) orientações para ações visando mineração de qualidade, com características sustentáveis.

O sistema de controle de uso que garanta a qualidade e as características do produto é essencial para a manutenção e sucesso da IG.

A definição da área geográfica deverá ser nos limites do município de Pirenópolis, que está localizado na mesorregião do leste goiano que pertence à microrregião do Entorno de Brasília. O município fica cerca de $120 \mathrm{~km}$ de Goiânia e $140 \mathrm{~km}$ de Brasília, entre os paralelos 15³0' e 16¹0' S e os meridianos 4850' e 49¹0'W. Os limites do município no nordeste com Cocalzinho de Goiás, no leste com Corumbá de Goiás, no sudeste com Abadiânia, no sul com 
Anápolis, no sudoeste com Petrolina de Goiás, no oeste com Jaraguá e São Francisco de Goiás, no noroeste com Goianésia e no norte com Vila Propício.

A representação gráfica ou figurativa da IG se mostra importante fator para agregar valor ao signo distintivo, facilitando a identificação da marca, tornando mais simples a divulgação da identidade visual da IG. Com isso, para transformar em realidade o potencial da IG é recomendável a criação de representação gráfica.

Depois da análise do cumprimento dos requisitos acima, o processo de registro da IG no INPI poderá ser iniciado com boas chances de sucesso, desde que as regras da IN 25/2013 sejam satisfeitas.

O registro da IG delimitará a área geográfica, restringindo o uso aos produtores e prestadores de serviços da região (no presente caso, os produtores organizados em entidade representativa) e onde, mantendo os padrões locais, impede que outras pessoas utilizem o nome da região em produtos ou serviços indevidamente.

\section{Considerações Finais}

No presente caso, em razão da natureza e da singularidade do produto bem como pela organização dos envolvidos na mineração e comercialização das Pedras de Pirenópolis, concluímos pela possibilidade de registro com sucesso no INPI dos signos distintivos Marca Coletiva, Marca de Certificação, Indicação de Procedência ou Denominação de Origem.

No entanto, as possíveis entidades legitimadas devem escolher o signo distintivo de sua preferência e, seguindo o exemplo de sucesso da Denominação de Origem das Pedras do Noroeste do Rio de Janeiro, concluímos que a melhor opção é a implementação do registro da IG por Indicação de Procedência e Denominação de Origem.

As vantagens diretas são a consolidação do nome "Pedras de Pirenópolis", com aumento das vendas, da produtividade, da qualidade do produto, maior organização dos produtores, definição de critérios técnicos de extração, manuseio e qualidade, possibilidade de exportação, entre outros benefícios.

A Denominação de Origem e a implementação de controle de uso também ajudarão no desenvolvimento sustentável da região, em melhorias nas técnicas de extração e manejo com melhor aproveitamento dos recursos naturais, além da preocupação com o desenvolvimento humano que a organização dos produtores certamente acarretará.

Entre as vantagens indiretas está a divulgação do nome do município, o que possibilitará a melhoria da exploração econômica do turismo local, com retorno financeiro em diversas áreas, como, restaurantes, hotéis, pousadas, comércio, gerando empregos e contribuindo para o desenvolvimento regional.

\section{Referências}

AGÊNCIA NACIONAL DE MINERAÇÃO. Desempenho do Setor Mineral em GO e DF, (2017). 2017. Disponível em: <http://www.anm.gov.br/dnpm/publicacoes-economia-mineral/arquivos/ desempenho_mineral_go_df_2017/view >. Acesso em: 10 jun. 2018. 
BRASIL. Lei no 10.973, de 2 de dezembro de 2004. Dispõe sobre incentivos à inovação e à pesquisa científica e tecnológica no ambiente produtivo e dá outras providências. Disponível em: $<$ http://www.planalto.gov.br/ccivil_03/_Ato2004-2006/2004/Lei/L10.973.htm>. Acesso em: 14 maio 2018.

Lei $\mathbf{n}^{\circ}$ 9.279, de 14 de maio de 1996. Regula direitos e obrigações relativos à Propriedade Industrial. Disponível em:<http://www.planalto.gov.br/ccivil_03/leis/19279.htm>. Acesso em: 14 maio 2018.

CONCEIÇÃO, Luana Fantinatti da et al. Geologia e Turismo: perspectivas para a geoconservação e a promoção do geoturismo no município de Pirenópolis-Go. Ateliê Geográfico, Goiânia, v. 3, n. 3, p. 74-91, 2009. Disponível em: < https://www.revistas.ufg.br/atelie/article/viewFile/8587/6107>. Acesso em: 31 out. 2018.

GIL, A. C. Como elaborar projetos de pesquisa. 4. ed. São Paulo: Atlas, 2012.

INSTITUTO BRASILEIRO DE GEOGRAFIA E ESTATÍSTICA (IBGE). Pirenópolis: panorama. [2018]. Disponível em: < https://cidades.ibge.gov.br/brasil/go/pirenopolis/panorama > . Acesso em: 10 jun. 2018.

INSTITUTO NACIONAL DA PROPRIEDADE INDUSTRIAL (INPI). Guia básico de indicação geográfica. [2018]. Disponível em: <http://www.inpi.gov.br/menu-servicos/indicacao-geografica $>$. Acesso em: 10 jun. 2018.

Indicação Geográfica no Brasil. 2015. Disponível em: <http://www.inpi.gov.br/menuservicos/indicacao-geografica/indicacao-geografica-no-brasil>. Acesso em: 15 jun. 2018

Instrução Normativa no 25, de 21 de agosto de 2013. Estabelece as condições para o Registro das Indicações Geográficas. 2013. Disponível em: <http://www.inpi.gov.br/legislacao-1/ in_25_21_de_agosto_de_2013.pdf >. Acesso em: 27 maio 2018.

Resolução INPI no 75/00 28/11/2000. Procedimento para registrar uma indicação geográfica. [2018]. Disponível em: <www.wipo.int/edocs/lexdocs/laws/pt/br/br070pt.pdf>. Acesso em: 14 maio 2018.

PIRENÓPOLIS. Portal virtual. [2018a]. Disponível em: <http://www.pirenopolis.go.gov.br/ municipio >. Acesso em: 10 jun. 2018.

PIRENÓPOLIS. [2018b]. Disponível em: <https://pt.wikipedia.org/wiki/Piren\%C3\%B3polis>. Acesso em: 10 jun. 2018.

REVISTA DA PROPRIEDADE INDUSTRIAL (RPI). Resolução $\mathbf{n}^{\mathbf{0}}$ 22/2013 de 18 de março de 2013. Rio de Janeiro, 2013. Disponível em: < http://revistas.inpi.gov.br/rpi/> . Acesso em: 27 maio 2018.

SERVIÇO BRASILEIRO DE APOIO ÀS MICRO E PEQUENAS EMPRESAS (SEBRAE). Marcas

e Patentes - Invenção: marcas e patentes são diferenciais competitivos que ajudam a ampliar a participação de MPE's e empreendedores individuais no mercado. 2016. Disponível em: <http://www.sebrae.com.br/sites/PortalSebrae/ufs/mt/artigos/o-que-e-marca,6ac62a734bc6a510 VgnVCM1000004c00210aRCRD > . Acesso em: 15 jun. 2018.

VEPRAPIRI. Um passeio por Pirenópolis, joia colonial no interior de Goiás. 2017. Disponível em: <http://vemprapiri.com.br/vc-em-piri/um-passeio-por-pirenopolis-interior-de-goias/>. Acesso em: 31 out. 2018. 


\title{
Sobre os autores
}

\begin{abstract}
Alessandro Aveni
E-mail: alessandro@unb.br

Doutor em Ciências Políticas, pela Universidade de Milan e em Administração, pela Universidade Cormercial Luigi Bocconi, ambas na Itália; mestre em Geografia, pela Universidade de Brasília (UnB); especialista em Estratégia Empresarial, pela Fundação Getúlio Vargas (FGV); e bacharel em Administração, pela UnB.

Endereço profissional: Centro de Apoio ao desenvolvimento tecnológico CDT/UNB. Campus Darcy Ribeiro Brasília, DF. CEP: 70910-900.
\end{abstract}

\section{Pedro Anisio de Camargo Alves}

E-mail: pedroanisioalves@gmail.com

Advogado da Empresa Brasileira de Pesquisa Agropecuária (Embrapa), onde atua na defesa dos interesses da empresa na Gerência Jurídica - Ação Contenciosa (GJC/ACON), e sócio do escritório de Advocacia Andrade Camargo Portela especializado em Assessoria Jurídica Empresarial com a função de Coordenador na área de Propriedade Intelectual.

Endereço Profissional: Embrapa Sede, Parque Estação Biológica - PqEB s/nº, Brasília, DF. CEP: 70770-901; e Andrade Camargo Portela Assessoria Jurídica Empresarial, SBS Qd. 02 Ed. Prime Sobreloja 206, Brasília, DF. CEP: 70070-120.

\section{Priscilla Marmentini}

E-mail: priscilla.marmentini@embrapa.br

Advogada da Empresa Brasileira de Pesquisa Agropecuária (Embrapa), onde atua na defesa dos interesses da empresa na Secretaria de Inovação de Negócios -Coordenadoria de Suporte Jurídico à Inovação e Negócios (SIN/CSJ).

Endereço Profissional: Embrapa Sede, Parque Estação Biológica - PqEB s/n, Brasília, DF. CEP: 70770-901. 